\title{
Deterioration and Microstructural Characterization of Reinforced Concrete Beam Buried in Lagoon and Fresh Waters
}

\author{
U. T. Igba ${ }^{\mathrm{a}, *}$, J. O. Akinyele ${ }^{\mathrm{a}}$, F. M. Alayaki ${ }^{\mathrm{a}}$, S. I. Kuye ${ }^{\mathrm{b}}$, S. O. Oyebisi ${ }^{\mathrm{c}}$ \\ ${ }^{a}$ Department of Civil Engineering, Federal University of Agriculture, Abeokuta, Ogun State, NIGERIA. \\ ${ }^{b}$ Mechanical Engineering Department, Federal University of Agriculture, Abeokuta, Ogun State, NIGERIA. \\ ${ }^{c}$ Department of Civil Engineering, Covenant University, Ota, Ogun State, NIGERIA.
}

\begin{abstract}
The effect of the sulphate attack on reinforced concrete structures in Lagos lagoon environment has become a concern for stakeholders in the construction industry. This study investigated the flexural strength and microstructure of reinforced concrete beams for a period of 365 days. Thirty beams with dimension $150 \mathrm{~mm} \times 150 \mathrm{~mm} \times 600 \mathrm{~mm}$ were cast using grade 30 concrete with water cement ratio of 0.45 and cured for 28, 90 and 365 days, in both lagoon and fresh water. Flexural strength and microstructural test were carried out. The result showed that the flexural strength of concrete submerged in fresh and lagoon water were 24.6 and $20.3 \mathrm{~N} / \mathrm{mm}^{2}$ respectively. The microstructure also confirmed the fact that specimens submerged in the lagoon had more defects and deterioration than the sample cured in fresh water at 365 days.
\end{abstract}

Keywords: flexural strength, lagoon water, fresh water, concrete

\section{INTRODUCTION}

Concrete is considered durable when exposed to both physical and chemical changes during its entire life span, with little or no impact [1]. Researchers have found out that structures in marine or sea environment, have an early degradation in such environments [2-5]. Degradation occurs when pervious concrete allows the passage of salty water. Permeable concrete most often leads to deterioration, especially when the outward environments are exposed to deleterious chemicals. Deterioration can come in the form of degradation of materials exposed to deleterious surfaces or by internal corrosion of reinforcement. Usually, cracks are the initial visible effect from increased concrete degradation [6]. The rate of entry of ocean and sea water into concrete can either have large or small pores with the former allowing easier entry of ocean and sea water into concrete, while the latter slows the pace at which certain waters penetrate concrete [7]. Moisture was one of the factors in which chemical compounds were transmitted, which influenced the movement of concrete matrix as a result of the pore distribution within the concrete [8].

${ }^{*}$ Corresponding author (Tel: +234 (0)803 396 9414)

Email addresses: igbaut@funaab.edu.ng (U. T. Igba), olawaleakinyele@gmail.com (J. O. Akinyele), alayakifm@funaab.edu.ng (F. M. Alayaki),

ibiyemikuye@yahoo.com (S. I. Kuye),

solomon.oyebisi@covenantuniversity.edu.ng (S. O. Oyebisi)
Concrete in soil and groundwater having dissolved sulfate, will be destroyed by the attack of sulphate. The degree of damage depends on content of the sulfate in the environment, the movement of water, composition of the cement, properties of the concrete, and the transport mechanism of the solution in the concrete [9].

The major sources of sulphate ions for external sulphate attack contained calcium, magnesium and sodium sulphates [10]. Calcium, sodium and potassium sulphate attacks were rated as mild, while magnesium and ammonium sulphate attacks were potentially more serious in their acts as they attacked more concrete components [11].

Chemically interacted sulphate ions with cement paste components resulted in cracking, loss of adhesion and expansion of cement hydration products due to thaumasite, gypsum and ettringite formation [12]. Microstructure was an advanced system that changed immensely during concrete hydration process, it was ultimately used to determine the effect of the field transportation of chemical substances on concrete and used to determine their eventual service life [13]. The effect of sulphate attack led to spalling of the concrete and the exposure of reinforcements as shown in Fig. 1 of a bridge pile caps in Lagos Nigeria.

Sulfate attack is generally attributed to the reaction of sulfate ions with calcium hydroxide and calcium aluminate hydrate to form gypsum and ettringite. There was a direct relationship between the water-cement ratio and the con- 


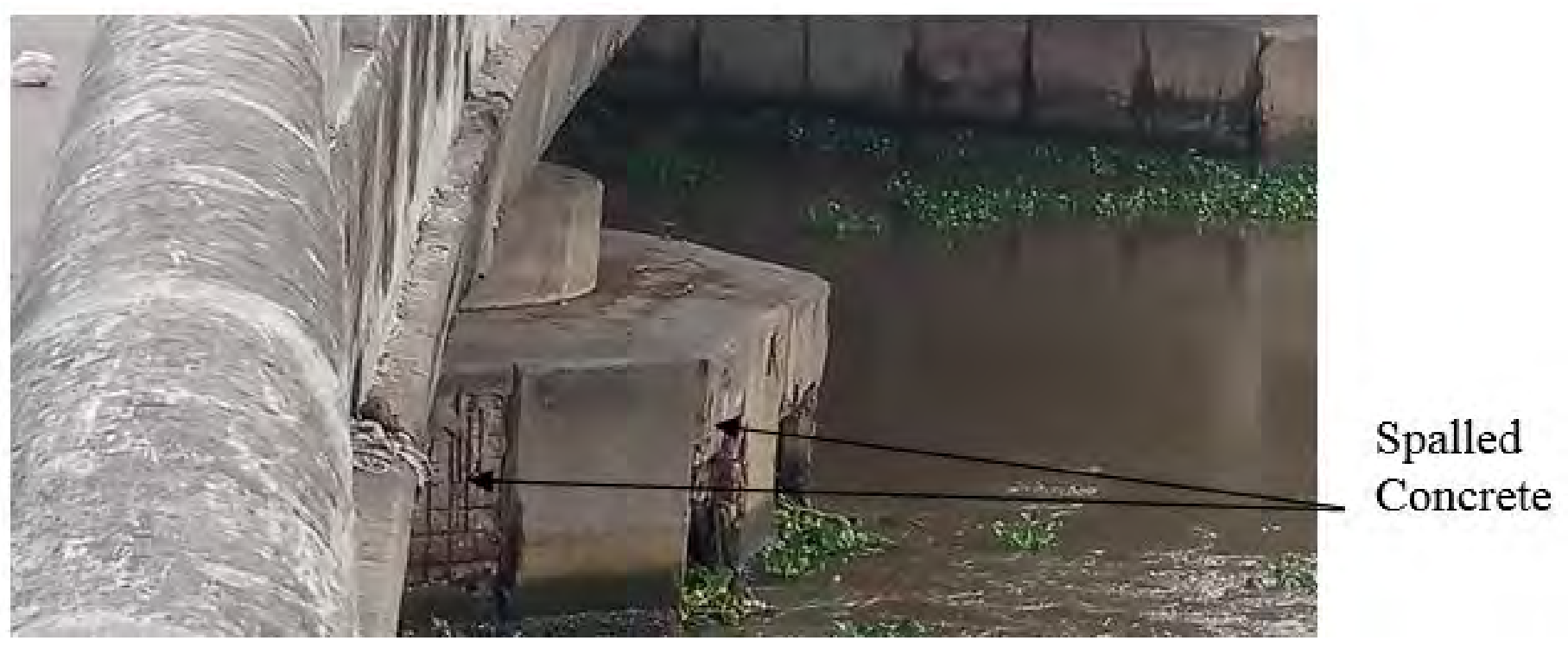

Figure 1: Concrete spalling of the pile cap of Carter bridge in Lagos, Nigeria.

crete strength. It was reported that the concrete strength was stronger when a lesser quantity of water was used [14]. Concrete was reported to have a lower permeability and higher strength when the water cement ratio was between 0.4 and 0.5. It was also reported that when concrete was prepared with high water cement ratio, bleeding and segregation occurred in the concrete [15]. This research aimed at investigating the rate of deterioration of reinforced concrete structures buried in the Lagos lagoon for a period of one year and to examine the microstructural changes that occur as a result of the sulphate attack on the reinforced concrete elements.

\section{RESEARCH METHODOLOGY}

\subsection{Materials}

Dangote $3 \times$ Grade 42.5 R Portland Limestone Cement (PLC) was obtained and used to meet the specifications of [16] as a binder for reinforced concrete beams, other materials include fine aggregate, coarse aggregate, steel reinforcement, and water. Fine aggregate (FA) was sieved through $4.75 \mathrm{~mm}$ to obtain sand of grading complying with zone IV with percentage passing of 95$100 \%$. Fine aggregate (FA) which was free from salt and other impurities after it was obtained from River Ogun. The sand was later washed using fresh borehole water and dried after it was obtained at Lat: $07^{\circ} 04^{\prime} 47.8$ ' $\mathrm{N}$ and Long: $03^{\circ}$ 18' 8.94" E from Ogun state. The coarse aggregate (Granite) with a maximum size of $12 \mathrm{~mm}$ was collected from a Quarry-site at Alabata area of Abeokuta, it passed through $14 \mathrm{~mm}$ sieve and conformed with [17]. Borehole water with no trace of suspended particles and chemical substances was used for mixing concrete at Civil Engineering Laboratory, University of Lagos which complied with [18] while samples were cured in the Lagoon and in 5 drums of 160 liters containing fresh water.
Steel was obtained from a local construction material supplier at Oshodi area, Lagos State, Nigeria. Thirty reinforced concrete beams with five replicates were prepared and cast as a prototype for this research. The main steel reinforcements were made of $12 \mathrm{~mm}$, while the links were made of $8 \mathrm{~mm}$ in diameter respectively. The beam spanned $600 \mathrm{~mm} \times 150 \mathrm{~mm} \times 150 \mathrm{~mm}$ in length, depth and width respectively.

\subsection{Sample Preparation}

\subsubsection{Concrete mix design}

$$
\begin{aligned}
\text { Target strength } & =f_{\text {target }}=f_{c k}+1.65 \times s \\
& =30+1.65 \times 4.0 \\
& =36.6 \mathrm{~N} / \mathrm{mm}^{2}
\end{aligned}
$$

where $f_{\text {target }}$ is the target mean strength, $f_{c}$ is the specified characteristic, $k$ is a constant (taken as 1.64 for a $5 \%$ defective level) and $\mathrm{s}$ is standard deviation taken as 4 .

Calculation of aggregate content $\left(f_{a}\right.$ and $\left.c_{a}\right)$ :

$$
\begin{gathered}
V_{c b}=\frac{W}{Y_{w}}+\frac{C}{Y_{w} \times S_{c}}+\frac{F_{a}}{Y_{w} \times S_{f a} \times(p)} \\
V_{c b}=\frac{W}{Y_{w}}+\frac{C}{Y_{w} \times S_{c}}+\frac{C_{a}}{Y_{w} \times S_{c a} \times(1-p)}
\end{gathered}
$$

where $V$ is absolute volume of concrete $=$ gross volume $1 \mathrm{~m}^{3}$ minus volume of entrapped air, $S_{c}$ is specific gravity of cement $=3.0, S_{c}$ is specific gravity of sand $=2.6, S_{c}$ is specific gravity of granite = $2.79, Y_{w}=1000, W$ is mass of water per cubic metre of concrete in kg, $C$ is mass of cement per cubic metre of concrete in $\mathrm{kg}, P$ is ratio of fine aggregate to total aggregate by absolute volume, $f_{a}, C_{a}$ are total mass of fine and coarse aggregate per cubic 
metre of concrete in $\mathrm{kg}, S f_{a}, S C_{a}$ are specific gravity of saturated surface of dry fine and coarse aggregate. Estimation of entrapped air for $10 \mathrm{~mm}$ aggregate $=3.0 \%$ volume of concrete. Grading of fine aggregate $=$ Zone 4 . $\%$ proportion of fine aggregate $=38 \%$.

Mix Design: Water cement ratio $=0.45$; approximate water content $(\mathrm{kg})$ per cubic metre of concrete for $12 \mathrm{~mm}$ maximum aggregate size for 15 to $30 \mathrm{~mm}$ slump $=205$

$$
\text { Cement }=\frac{205}{0.45}=456 \mathrm{~kg}
$$

Substituting the values in Eq. (2),

$$
\begin{gathered}
100=205+\frac{456}{3.0}+\left(\frac{1}{0.38} \times \frac{f_{a}}{2.6}\right) \\
f_{a}=635 \mathrm{~kg}
\end{gathered}
$$

Substituting the values in Eq. (3), we get

$$
\begin{gathered}
1000=205+\frac{456}{3.0}+\left(\frac{1}{0.62} \times \frac{C_{a}}{2.79}\right) \\
C_{a}=1112 \mathrm{~kg}
\end{gathered}
$$

Water: Cement: Fine aggregate: Coarse Aggregate $\left(W: C: f_{a}: C_{a}\right)$

$$
\begin{aligned}
\left(W: C: f_{a}: C_{a}\right)= & 205: 456: 635: 1112 \\
& =0.45: 1: 1.39: 2.44
\end{aligned}
$$

\subsubsection{Casting of concrete}

The mix design for the concrete was in the ratio of 1:1.39:2.44 for cement, fine aggregate and coarse aggregate respectively, with a watercement ratio of 0.45 , all based on [19] standard method. The batching of concrete tests samples was by weight in order to eliminate errors due to variation in the proportion of voids contained in a specified weight, in conformity with [20], the aggregate size of $12 \mathrm{~mm}$ was mixed with sand and cement mixture. The beam size used was $600 \mathrm{~mm}$ $\times 150 \mathrm{~mm} \times 150 \mathrm{~mm}$. With each sample having a replicate of five. Each of the constituent was weighed and mixed until a uniform mixture was achieved, the mould were oiled properly to prevent the concrete from sticking to the mould and for easy removal of beams. The concrete mixes were left inside the mould for about 24 hours before removing from the moulds, this was to allow proper setting of concrete. The curing of concrete was done according to [20], the beams were immersed inside both fresh water drum and fully submerged inside the lagoon water such that the beams were completely covered with water. On each testing day the samples were brought out of both the drum and the lagoon and allowed to dry before the weight was determined.

Grade 30 concrete was used in this research, fifteen samples were buried in the lagoon water and designated as BL30, while fifteen samples were cured in fresh water which were used as the control sample designated as BF30.

\subsection{Test for Hardened Concrete}

\subsubsection{Flexural strength test}

Flexural strength was carried out to determine the measurement of the force that was required to rupture a material and also to find the extent at which the material was elongated before failure occurred as shown in Fig. 2. Tests were performed using a $600 \mathrm{kN}$ capacity Zhejiang Tugong Universal Testing Machine at Civil Engineering Laboratory of the Federal University of Agriculture Abeokuta, Ogun state, Nigeria.

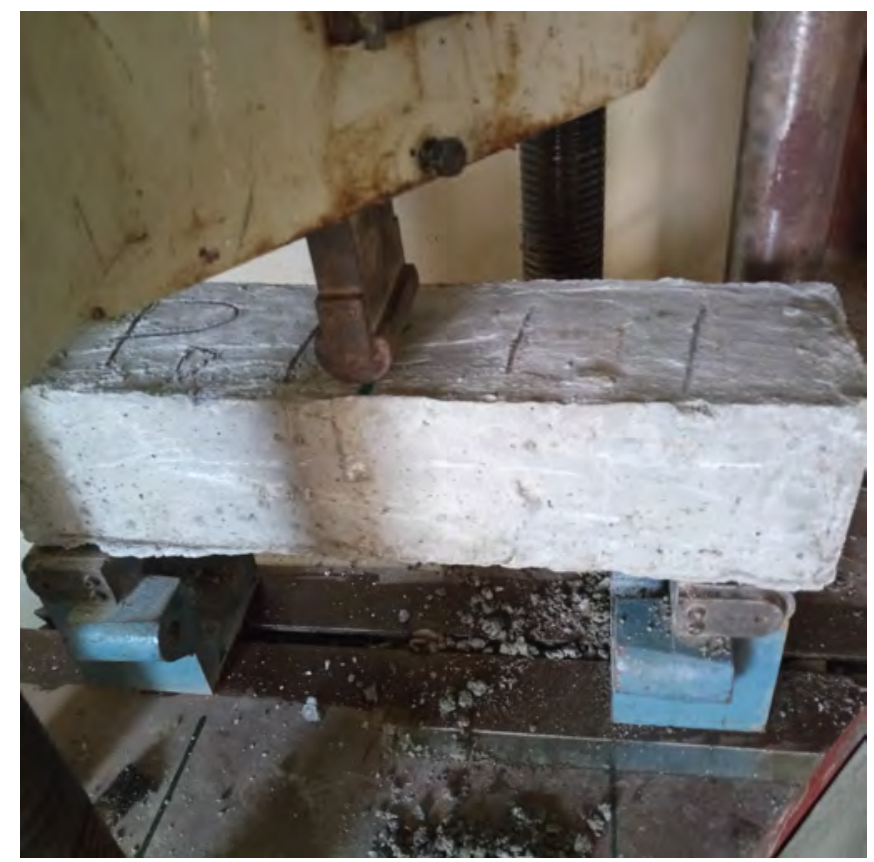

Figure 2: Flexural strength test of reinforced concrete beam not (location map of study areas).

The flexural strength test was carried out on the beam specimen for BL30 and BF30. For the flexural strength performance, a three-point loading test was adopted in accordance with [21] and forces applied to the beams were perpendicular to the failure plane. The beam was then marked where made contact with the supports and the top side that made contact with the point load, the specimen was placed in the testing machine, correctly centered with the longitudinal axis of the specimen at right angles to the casting position, the specimen was loaded until failure occurred, the ultimate load was read and recorded. Also, the flexural strength test was carried out on five samples for each. After the test, the cross-section at each end and at the center was measured. The average height and depth were computed. The average flexural strength of the beams cast was determined by applying the formula illustrated in Eq. (4).

$$
f=\frac{P L}{b d^{2}}
$$

where $f$ is flexural strength (in $\mathrm{N} / \mathrm{mm}^{2}$ ), $P$ is load in $\mathrm{N}$ applied to the specimen, $L$ is length in $\mathrm{mm}$ of the span on which the specimen was supported 


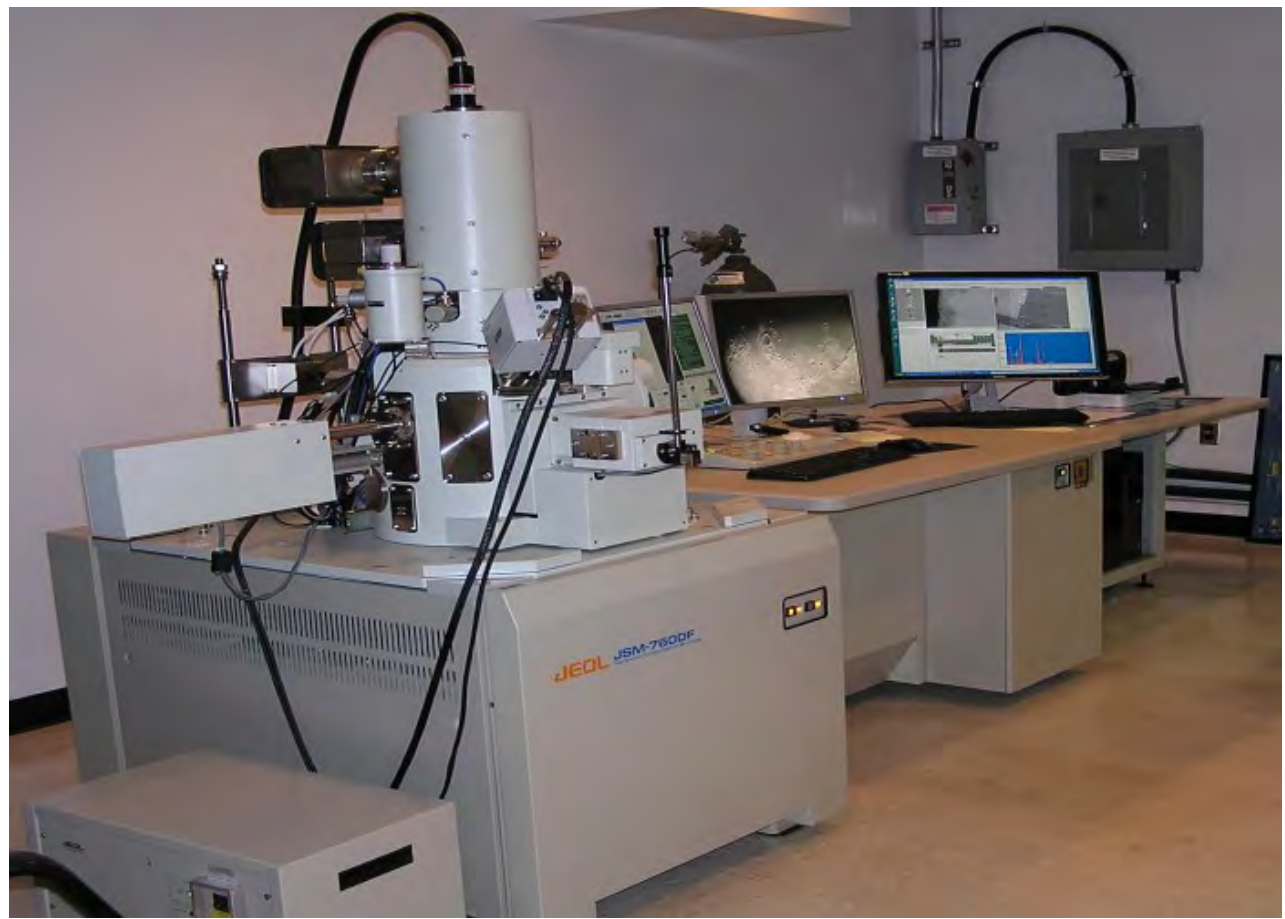

Figure 3: SEM complete system.

(600), $b$ is measured width in mm of the specimen (150) and $d$ is measured depth in $\mathrm{mm}$ of the specimen (150).

\subsubsection{Scanning electron microscopy}

Samples were placed into the specimen chamber of about $10 \mathrm{~mm} \times 10 \mathrm{~mm} \times 15 \mathrm{~mm}$ size and were mounted on a specimen holder called a specimen stub. Samples were coated with ultrathin coating of electrically conductive material, either by low-vacuum sputter coating or highvacuum evaporation accumulated on the sample. SEM instruments placed the specimen in a relative high-pressure chamber where the working gap was small and the optical electron column was pumped accordingly to retain sufficiently low vacuum at the electron device. The high-pressure area around the sample in the SEM neutralized charge and provided secondary electron signal amplification.

The machine used for the Scanning Electron Microscopy (SEM) analysis was JEOL-JSM$7600 \mathrm{~F}$ field Scanning Electron Microscope, shown in Fig. 3.

\subsubsection{Energy dispersive spectroscopy (EDS)}

The Skyray EDXRF 3600B's energy dispersive spectroscopy (EDS) feature presented us with a graphical representation of the elemental composition. Physical analysis of this spectrum revealed the dominant elements and small elements present in the concrete samples. Quantitative Element analysis of the concrete samples for BL30, and BF30 were determined.

\section{FINDINGS AND DISCUSSIONS}

\subsection{Result of Chemical Composition Test on Lagoon Water and Fresh Water}

The lagoon water showed that it possesses higher salinity, higher content of sulphate and chloride with values of $469.7,20$, and $260 \mathrm{mg} / 1$ compared to that of fresh water with reduced quantities with values of $28.9,6$ and $16 \mathrm{mg} / \mathrm{l}$.

\subsection{Flexural Strength Test}

The flexural strength of BL30 at 28 days had the optimum average flexural strength of $25.3 \mathrm{~N} / \mathrm{mm}^{2}$ which was due to the chemical reaction between the lagoon water and the Ettringite, $\mathrm{Ca}(\mathrm{OH})^{2}$, and $\mathrm{C}-\mathrm{S}-\mathrm{H}$ gel which were actively generated from an early age.

According to [22], the chemical reaction between the lagoon water and the Ettringite, $\mathrm{Ca}(\mathrm{OH})^{2}$, and $\mathrm{C}-\mathrm{S}-\mathrm{H}$ gel which were actively generated from an early age.

Tricalcium silicate + Water $=$

Calcium silicate hydrate

+ lime (Calcium hydroxide) + heat

$$
\begin{aligned}
2 \mathrm{Ca}_{3} \mathrm{SiO}_{5}+7 \mathrm{H}_{2} \mathrm{O}= & 3 \mathrm{CaO} \cdot 2 \mathrm{SiO}_{2} \cdot 4 \mathrm{H}_{2} \mathrm{O} \\
& +3 \mathrm{Ca}(\mathrm{OH})_{2}+\text { Heat }
\end{aligned}
$$

Dicalcium silicate + Water $=$

Calcium silicate hydrate

+ lime (Calcium hydroxide) + heat 
Table 1: Comparison of the chemical composition of Lagoon water and Fresh water.

\begin{tabular}{lllll}
\hline Property & $\begin{array}{l}\text { Concentration } \\
\text { curing (mg/) } \\
\text { Lagoon water }\end{array}$ & Fresh water & $\begin{array}{l}\text { Concentration at the end of cur- } \\
\text { Lag(mg//) } \\
\text { Lagoon water }\end{array}$ & Fresh water \\
\hline Colour & Dirty light yellow & Colourless & Dirty light yellow Colourless \\
Odour & Odourless & Unobjectionable & Objectionable & Odourless \\
SEDIMENT mg/l & 5 & 3 & 18 & ND \\
Oil \& Fats (mg/l) & 0.001 & ND & ND & ND \\
Detergent (mg/l) & ND & ND & ND & ND \\
PH & 7.2 & 7.2 & 6.9 & 6.9 \\
Nitrate (mg/l) & 2.62 & 0.55 & 7.28 & 2.32 \\
Sugar (Glucose mg/l) & ND & ND & ND & ND \\
Zinc (mg/l) & 2.7 & 0.6 & 7.36 & 2.4 \\
Phosphate (mg/l) & 0.01 & 0.01 & 0.02 & 6.01 \\
Sulphate (mg/l) & 7 & 2 & 20 & ND \\
Humic Substance (mg/l) & ND & ND & 260 & 16 \\
Chloride (mg/l) & 48 & 6 & 469.7 & 28.9 \\
Salinity (mg/l) & 86.7 & 10.8 & 0.42 & 0.06 \\
Iron (mg/l) & 0.1 & 0.03 & 650 & 190 \\
TDS (ppm) & 230 & 50 & &
\end{tabular}

$$
\begin{aligned}
2 \mathrm{Ca}_{2} \mathrm{SiO}_{4}+5 \mathrm{H}_{2} \mathrm{O}= & 3 \mathrm{CaO} \cdot 2 \mathrm{SiO}_{2} .4 \mathrm{H}_{2} \mathrm{O} \\
& +\mathrm{Ca}(\mathrm{OH})_{2}+\mathrm{Heat}
\end{aligned}
$$

$$
\begin{aligned}
& \begin{array}{l}
\text { Tricalcium Aluminate }+ \text { Gypsum }+ \text { Water } \\
=\text { Ettringite }+ \text { HEAT }
\end{array} \\
& \begin{aligned}
C_{3} A+3 C_{6} A S_{3} H_{32}+22 H_{2} O & =C_{6} A S_{3} H+H E A T \\
C_{4} A F+3 C S H_{2}+3 H_{2} O & =C_{6}(A F) S_{3} H_{32} \\
& =+(A F) H_{3}+C a\left(O H_{8} 2\right.
\end{aligned}
\end{aligned}
$$

It was observed that BL30 submerged in the lagoon behaved better at the early stages of curing than the BF30 submerged in fresh water for 28 days. The optimum strength after curing for a period of one year was recorded in BF30 with flexural strength of $24.6 \mathrm{~N} / \mathrm{mm}^{2}$ compared to BL30 with flexural strength value of $20.3 \mathrm{~N} / \mathrm{mm}^{2}$, confirming that reinforced concrete beam samples submerged in fresh water over a long period of time performed better than samples submerged in lagoon water with a linear increment from 28 to 365 days. Fig. 4 showed the result of the flexural test carried out on the beams. There was a final decrease in flexural strength from 28 days to 365 days by $19.76 \%$ for BL30 while there was a rise in strength from 28 days to 365 days by $84.96 \%$ for BF30. The rise and fall of the flexural strength of reinforced concrete sample buried in the salty lagoon water over a period of 365 days showed the activity of sulphate. This was evident that due to the prolonged sulphate attack on the reinforced concrete beam buried in lagoon water for a period of 365 days, there was a final reduction in flexural strength compared to reinforced concrete samples buried in fresh water which strength kept increasing geometrically. The reasons for the decrease in flexural strength were as a result of poor interfacial adhesion between the concrete and the reinforcement, due to the presence of sulphate and chloride attacking both the concrete and the steel reinforcement, and also the distortion in the microstructure caused by penetration of lagoon water and porous morphology of the lagoon water in the reinforced concrete beam.

\subsection{Deterioration Equation}

The formula to calculate a deterioration rate given a beginning and ending year is:

$$
P_{f}=P_{y}\left[1 \pm A_{c r}\right]^{n}
$$

Where $P_{f}$ is future year, $P_{y}$ is past year, $n$ number of forecast years after base year $(n>1)$ and $A_{c r}$ is annual deterioration rate.

The result for grade 30 flexural strength submerged for 28,90 , and 365 days were used to predict the deterioration rate for 5 years from Eq. 6 . The percentage of deterioration rate for 1 year, $2,3,4$ and 5 years decreased by $19.76,35.57$, $48.22,58.49$ and $66.74 \%$ respectively with flexural strength of $20.3,16.3,13.1,10.5$ and 8.42 $\mathrm{N} / \mathrm{mm}^{2}$ respectively for BL30.

Figures 5 and 6 below showed the physical appearance of reinforced concrete beam after a period of 365 days by visual examination of the reinforced concrete beam, the deterioration of a reinforced concrete beam from the external ingress of sulphate ions BL30 was dark grey and greenish in appearance, the reinforced concrete beam without any sign of deterioration BF30 was light grey/whitish color.

\subsection{Scanning Electron Microscopy}

Research has shown according to the results presented by $[23,24]$ that the microstructure of structural materials were largely determined by their mechanical properties.

In Figs. 8, 10 and 12 samples of concrete microstructures were observed. It was found that 


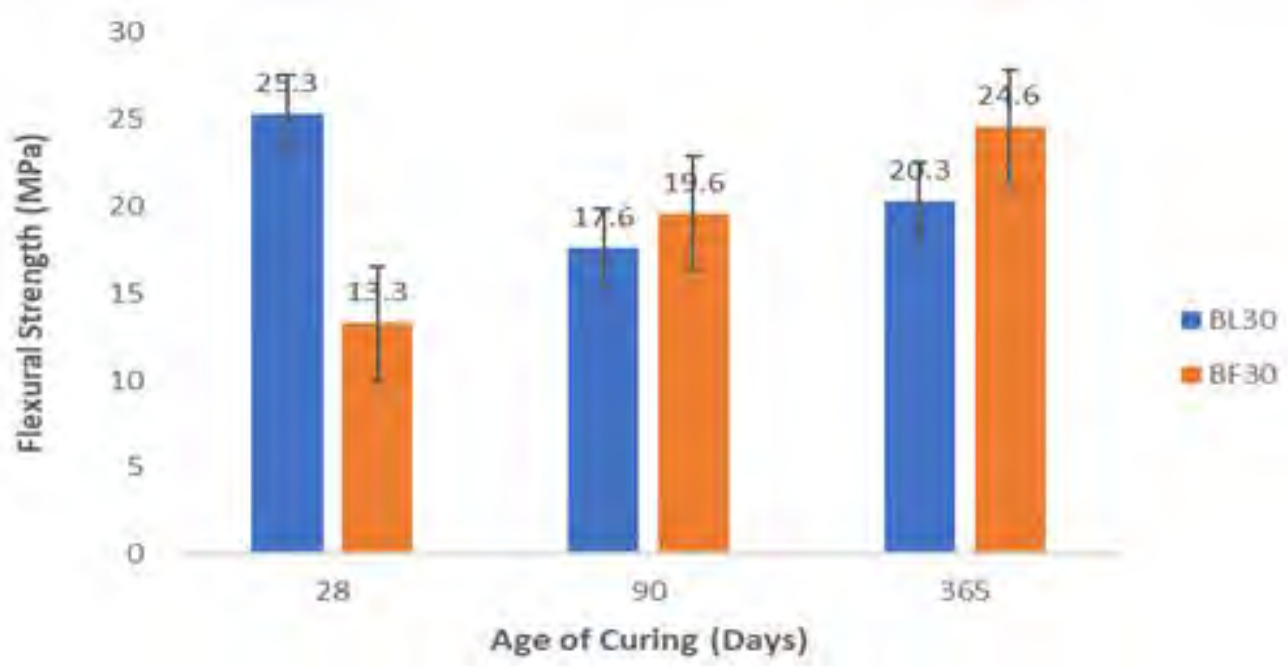

Figure 4: Flexural strength result

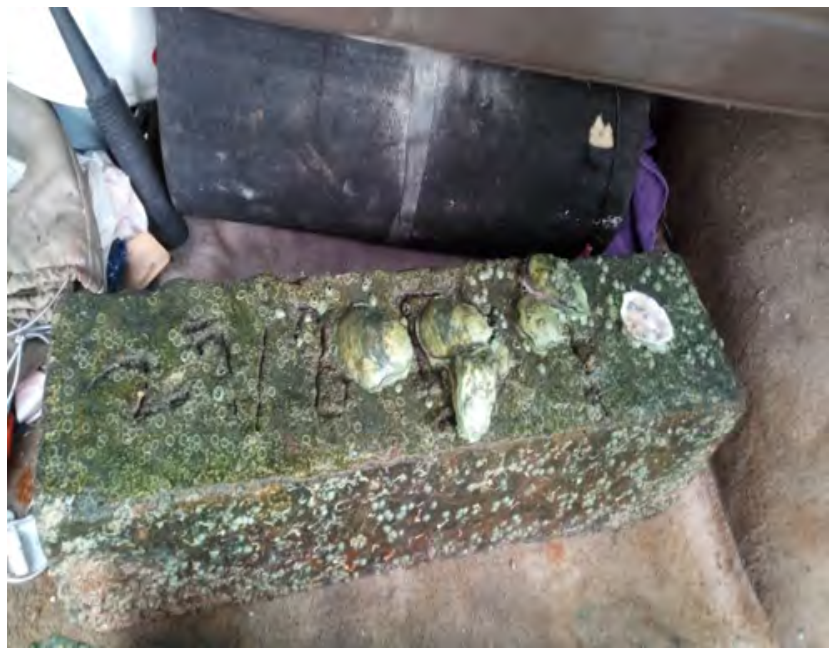

Figure 5: Beam buried in Lagoon water after 1 year.

the internal hydration substance, primarily calcium hydroxide, had a widely dispersed structure near the concrete micro-pores and microfractures. Similarly, a lot of fibrous and flocculent hydrated calcium silicate but no apparent corrosion or micro-damage products were found as there were no record of external sulphate ion concrete penetration.

BL30 indicated that there was an early strength for samples cured in lagoon water at 28 days compared to BF30, it indicated that the hydration reaction of cement was not achieved. The major issue with cement composites was that cement hydration materials had various irregular forms [25-27], resulting in the creation of a disordered matrix with several cracks and holes, degrading their performance, and reducing their strength [28-30].

BL30 at 90 days was more porous than BF30 with the passage of time the quantities of $\mathrm{Ca}(\mathrm{OH})_{2}$, Ettringite, and $\mathrm{C}-\mathrm{S}-\mathrm{H}$ gel were noticeable at magnification of $\times 10000$ for BL30 which

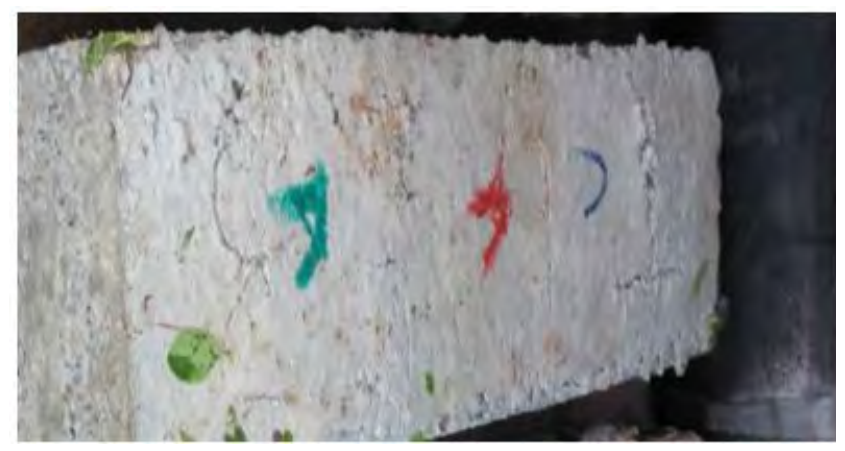

Figure 6: Beam buried in Fresh water after 1 year.

led to expansion and strength loss which agreed with [31, 32].

Many parts of small hydrating crystals and large holes existed for BL30 as seen in Figs. 7, 9 , and 11 having large micro holes. The key explanation for this was the small volume of hydration crystals and their unequal distribution in the cement matrix, resulting in the formation of very large pores and an overall decrease in the strength when compared to samples buried in fresh water.

At 365 days, it was observed that due to the fully submergence of samples buried in the lagoon water, samples ended having a microstructure with more defects, a lot of macro pores with decreased flexural strength were noticed in BL30 at the 365th day showing the vulnerability of sulphate damage of the concrete buried in lagoon water by physical salt weathering which depended on the pore structure which was similar to the research by [33] where the presence of small pore increased the capillary rise and also increased the surface area of evaporation which led to higher supersaturation of the pore solution that caused more damage.

The dark dolomite rim (BL30) seen in Figs. 7, 9 , and 11 were wide, dark-colored and occurred near the outer margin of the coarse aggregate particles. The rim was darker and more porous 
Table 2: Elements present in three-point spectra and the weight percentage for 28, 90, and 365 days at $10000 \times$ magnification.

\begin{tabular}{lcccccc}
\hline \multirow{2}{*}{ Element } & \multicolumn{2}{c}{ 28 days } & \multicolumn{2}{c}{ 90 days } & \multicolumn{2}{c}{ 365 days } \\
& BL30 (\%) & BF30 (\%) & BL30 (\%) & BF30 (\%) & BL30 (\%) & BF30 (\%) \\
\hline Silicon (Si) & 10.1 & 29.4 & 13.3 & 8.4 & 8.55 & 8.4 \\
Oxygen (O) & 12.3 & 42.0 & 22.6 & 45.3 & 37.3 & 36.4 \\
Calcium (Ca) & 51.1 & 32.6 & 60.4 & 35.5 & 41.1 & 41.2 \\
Magnesium (Mg) & 0 & 0 & 0.32 & 0.74 & 1.3 & 1.45 \\
Iron (Fe) & 2.09 & 2.99 & 2.5 & 1.26 & 6.2 & 4.24 \\
\hline
\end{tabular}

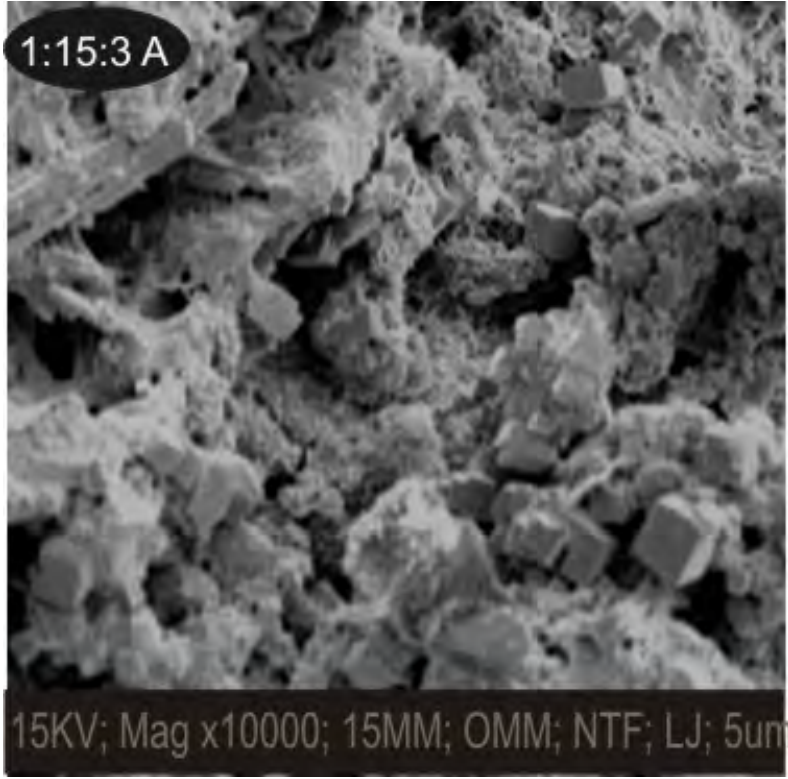

Figure 7: BL30 at 28days.

than the light-colored dolomite rim (BF30) which was less porous and exhibited fewer and smaller inter-crystalline voids than the dark dolomite rim. Voids in porous dolomite reaction rim were filled with Ca-, Mg- and O- rich materials. The Mg- and $\mathrm{O}$ - rich spots in cement paste indicated brucite.

\subsection{Energy Dispersive Spectroscopy (EDS)}

It was revealed that there was a small percentage of magnesium present compared to other elements. Calcium was the most predominant having optimum quantity at 90 days of curing with BL30 having more calcium element than BF30 from 28 days to 365 days.

The EDS spectra for 90 and 365 days were mainly calcium (Ca), silicon ( $\mathrm{Si}$ ) and oxygen (O), which formed the main elemental composition of the mineral phase. It was observed that there were trace amounts of magnesium present, which was attributed to Limestone Portland Cement which contained trace amounts of $\mathrm{MgO}$.

The result of the EDS agreed with [34] that more quantity of Calcium amounted from the leaching of Calcium $(\mathrm{Ca})$ which had significant effect on the physical characteristics of concrete. Leaching of Calcium $(\mathrm{Ca})$ led to the loss of mass, loss of alkalinity, and loss of flexural strength on samples submerged in the lagoon water.

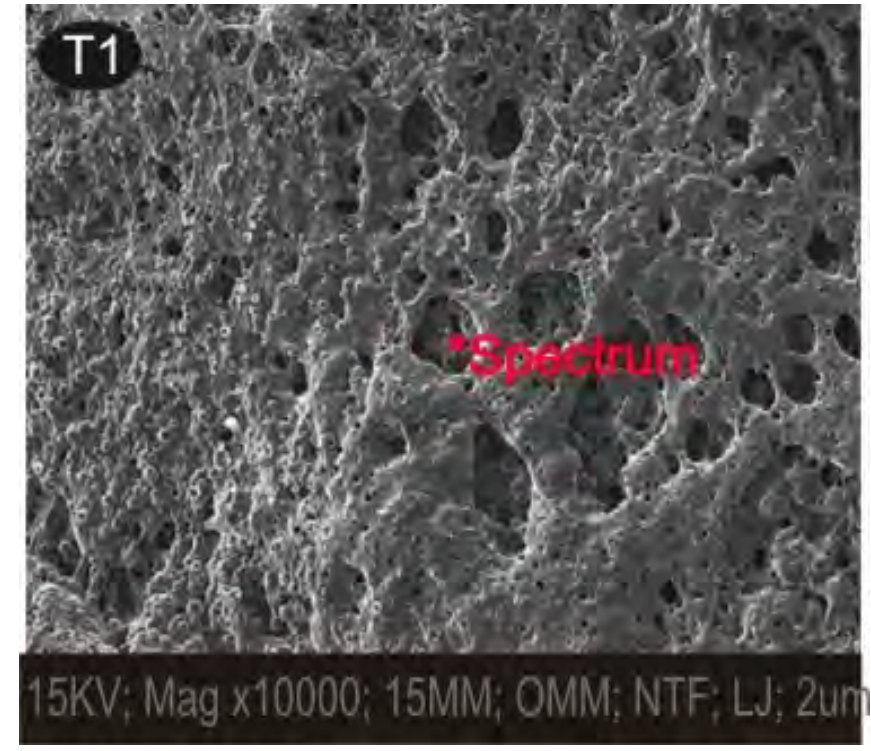

Figure 8: BF30 at 28 days.

The effect of deterioration of BL30 resulting from sulphate attack due to the formation of ettringite and gypsum and its subsequent expansion, was partially caused by the degradation of the calcium silicate hydrate C-S-H through leaching calcium compounds (Ca-) which was the most dominant element. This process led to loss in calcium silicate hydrate gel stiffness and an overall deterioration of the cement paste matrix which agreed with [35, 36]. Calcium and oxygen reacted to form Calcium oxide ( $\mathrm{CaO})$, magnesium and oxygen reacted to form Magnesium oxide ( $\mathrm{MgO})$.

It was seen that BL30 and $\mathrm{BF} 30$ had a $\mathrm{CaO}$ content of 84.51 and $49.67 \%$ at 90 days and 57.65 and $57.51 \%$ at 365 days respectively. Magnesium oxide for BL30 and BF30 had 0.53 and $1.23 \%$ at 90 days and 2.4 and $2.16 \%$ at 365 days, respectively. Calcium being the dominant element meant that cements with a calcium oxide $(\mathrm{CaO})$ additive were characterized by a much larger expansion compared to the magnesium oxide additive. In addition, the introduction of calcium oxide led to an early expansion process which invariably led to a decrease in the strength of concrete at increasing the content in cements. The small trace of magnesium seen was too small in amount to be fully responsible for the decrease in flexural strength in the reinforced concrete beams buried in lagoon water. 
Mazurok et al. [37] determined the cements with calcium oxide additive which were characterized by a much larger expansion compared to the magnesium oxide additive.

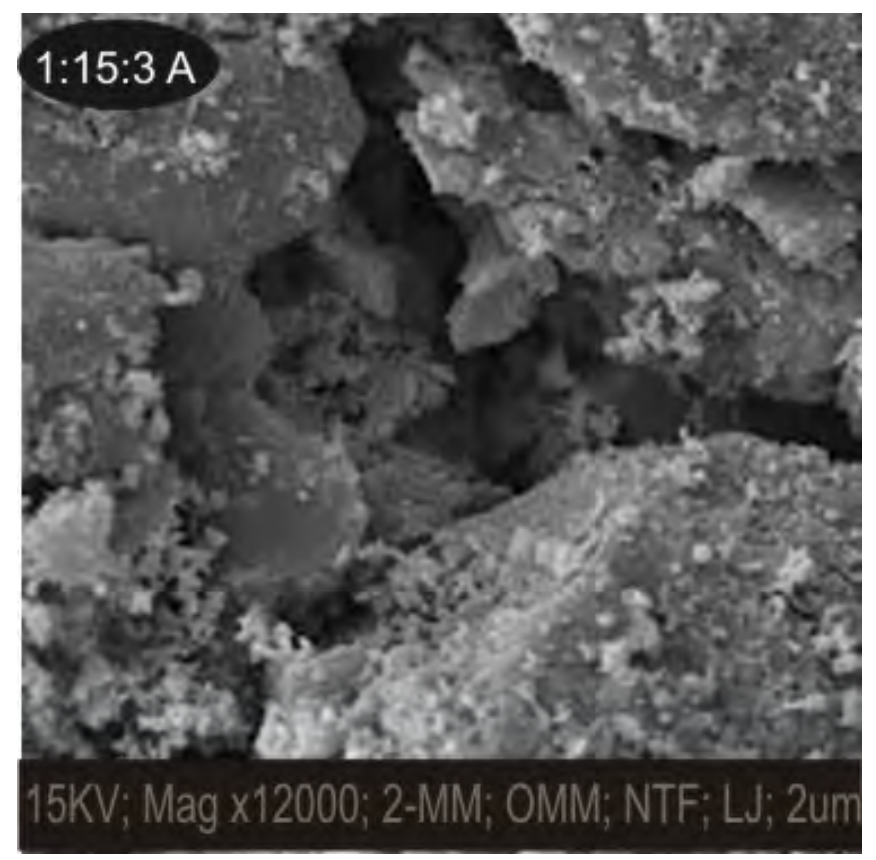

Figure 9: BL30 at 90 days.

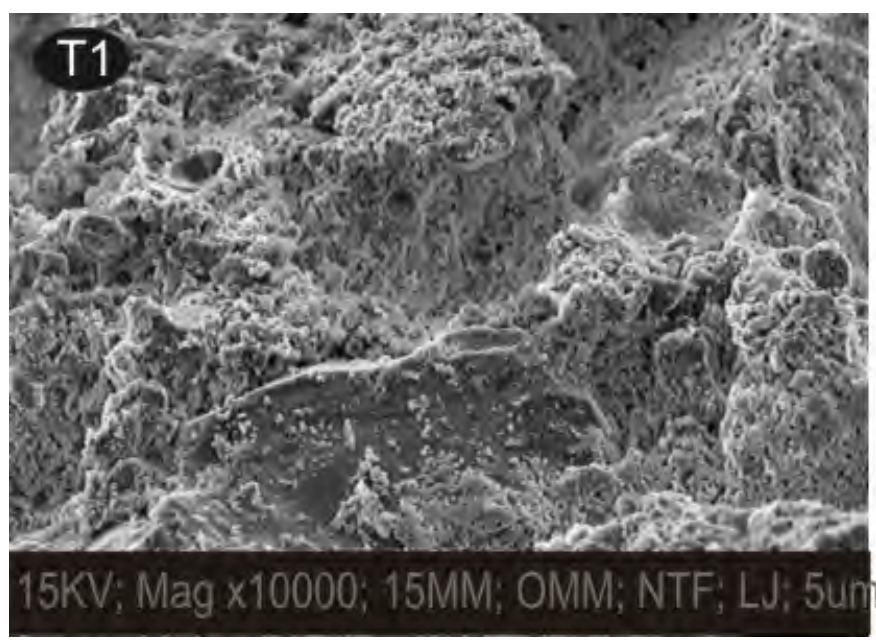

Figure 10: BF30 at 90 days.

\section{CONCLUSION}

It can be concluded that, upon exposure of concrete samples buried in lagoon water over a prolonged period of time, the physical damage in terms of the rate of deterioration that ensued were characteristically associated with increased porosity and loss of strength. There was an early increase in flexural strength for BL30 concrete samples compared to BF30 by $47.4 \%$ at 28 days of curing. At 365 days the reverse was the case as BL30 reduced in flexural strength by $17.5 \%$ when compared with BF30. There were lots of defect in the microstructures of the concrete that was

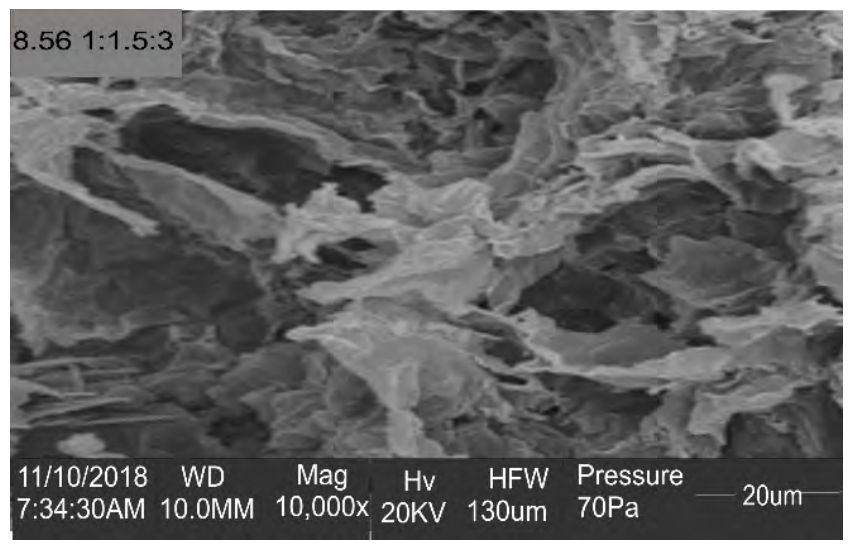

Figure 11: BL30 at 365 days.

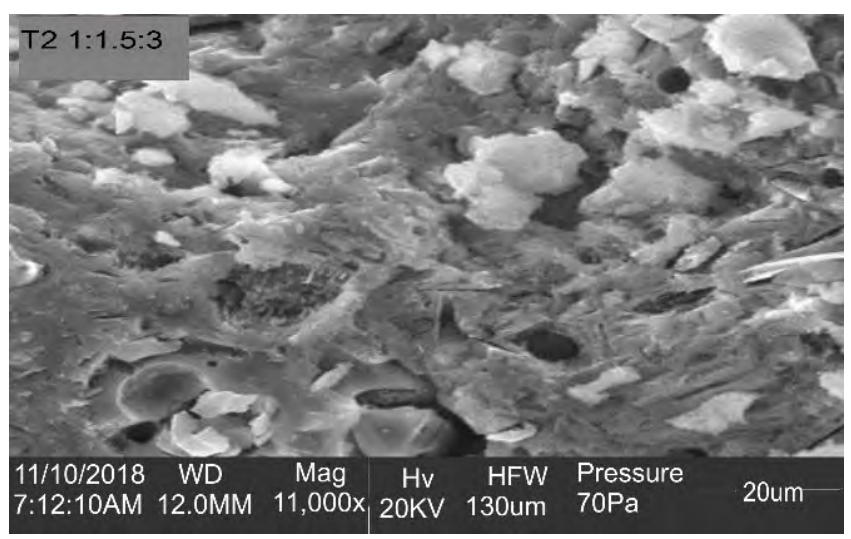

Figure 12: BF30 at 365 days.

buried in lagoon water, these samples had more micro pores in them when compared to the concrete samples buried in fresh water. BF30 had less defects in its microstructures which in turn increased the generation of components such as hydrated calcium silicates (C-S-H) crystals elements, which improved the composite mechanical properties. Calcium-Silica-Hydrate (C-S-H) was the major phase present which was influenced by the distribution of the particles as well as the size, shape and orientation of the particles. Capillary pores with wide diameters for BL30 were used as a means by which water under pressure penetrated the concrete matrix carrying dissolved salts from lagoon water, resulting in improved exposure to concrete porosity, pore depth and permeability of concrete samples buried in lagoon water.

\section{References}

[1] C. Karunakaran S.L., Rajkumar, P. Sharma, and A. Sharma, Handbook on Repair and Rehabilitation of RCC Buildings, Central Public Works Department, New Delhi India, 2002.

[2] K. Zaher and S. Samir, "Permeability and chloride penetration of concrete subjected to Gaza seawater exposures," Journal for Natural and Engineering Studies, vol. 9, no. 2, pp. 67-84, 2001.

[3] U. Igba, J. Akinyele, F. Alayaki, A. Adetiloye, O. Oluwatudimu, and S. Ehikhuenmen, "Effect of lagoon and fresh waters on the compressive and split tensile strength of grade 40 concrete," Journal of Science and Technology, vol. 4, pp. 30-34, 2018. 
[4] U. Igba, J. Akinyele, F. Alayaki, and S. Kuye, "Causes of failure in concrete elements buried in lagoon water," Engineering failure Analysis, vol. 10, pp. 425-432, 2019.

[5] A. Torres-Acosta and A. A. Sagues, "Concrete cracking by localized steel corrosion-geometric effects," ACI Materials Journal, vol. 101, no. 6, pp. 501-507, 2004.

[6] R. Stuart and I. Jason, "Behaviour of tilt-up precast concrete buildings during the 2010/2011 christchurch earthquakes," Structural Concrete, vol. 12, no. 4, pp. 234-240, 2011.

[7] A. Saleh, "Chloride induced corrosion and sulphate attack- a literature review on concrete durability," in The 3rd ACF International Conference ACF/VCA. Institute of Concrete Technology (UK) Elkem Materials South East Asia, Singapore, 2008

[8] K. Abu Al-Eis and I. LaBarca, "Evaluation of the uretek method of pavement lifting, rep. no. wi-02-07," Wisconsin Department of Transportation, Division of Transportation Systems Development, Madison, Wisconsin, 2007.

[9] S. Mouring and O. Barton, "Reinforced concrete beams externally retrofitted with advanced composites," Advanced Composite Materials, vol. 10, no. 2, pp. 139-146, 2001.

[10] W. Klemm and F. Miller, "Plausibility of delayed ettringite formation as a distress mechanism - consideration at ambient and elevated temperatures," in Proceedings, 10th International Congress on the Chemistry of Cement, vol. 4, no. 59, Gothenburg, Sweden, 1997, p. 10.

[11] O. Akinsola, A. Fatokun, and O. Ogunsanmi, "Investigation of salinity effect on compressive strength of reinforced concrete," Journal of Sustainable Development, vol. 5, no. 6, pp. 74-82, 2012.

[12] P. Mehta, "Sulphate attack on concrete: Separating myths from reality," Concrete International, vol. 22, no. 8, pp. 57-61, 2000.

[13] P. Dale, "Ten observations from experiments to quantify water movement and porosity percolation in hydrating cement paste," National Institute of Standards and Technology, U.S.A, 2005.

[14] M. Gambhir, Concrete Technology, 5th ed. Green Park Extention, New Delhi: McGraw Hill Education (India) Private Limited, 2013.

[15] S. Sumadi and Y. Lee, "Development of blended cements for water proofing application," Jabatan Struktur dan Bahan Fakulti Kejuruteraan Awam Universiti Teknologi Malaysia, 2008.

[16] "Nigerian industrial standard 441-1," Industrial Standard Order for cement manufacturing, distribution, classification and usage, Nigerian Industrial Standard, Lagos, Nigeria, 2014.

[17] "British standard en 12620," Aggregate from Natural Sources for Concrete, British Standard Institution, London, 2014.

[18] "British standard 1008," Mixing Water for Concrete: Specification for Sampling, Testing and Assessing the Suitability of water, British Standard Institution, London, 2002 .

[19] "British standards institution 8110-1," Structural use of concrete - Code of Practice for design and construction; British Standard Institution, London, 1997.

[20] "British standard en 12390-2," Testing Hardened Concrete - Part 2: Making and curing specimens for strength tests, British Standard Institution, London, 2009.

[21] "British standard code of practice," BS EN 12390-5: Testing Hardened Concrete: Flexural Strength of Test Specimens, 2009

[22] D. Lawrence, "Cement and water content of fresh concrete. significance of tests and properties of concrete and concrete making materials is004," Portland Cement Association: 2001, PCA, RP328, pp. 112-120, 2001.

[23] Q. Wang, J. Wang, C. Lu, B. Liu, K. Zhang, and C. Li, "Influence of graphene oxide additions on the microstructure and mechanical strength of cement," New Carbon Materials, vol. 30, no. 4, pp. 349-356, 2015.

[24] S. Lv, Y. Ma, C. Qiu, T. Sun, J. Liu, and Q. Zhou, "Appli- cation of microstructurally-designed mortars for studying early-age properties," Construction and Building Materials, vol. 49, pp. 121-127, 2013.

[25] C. Di Bella, M. Wyrzykowski, and M. Griffa, "Effect of graphene oxide nanosheets of microstructure and mechanical properties of cement composites," Microstructure and mechanical properties, Cement and Concrete Research, vol. 78, pp. 234-244, 2015.

[26] K. Scrivener, P. Juilland, and P. Monteiro, "Advances in understanding hydration of portland cement," Cement and Concrete Research, vol. 78, pp. 38-56, 2015.

[27] M. Bligh, M. Eurydice, and R. Lloyd, "Investigation of early hydration dynamics and microstructural development in ordinary portland cement using $1 \mathrm{hnmr}$ relaxometry and isothermal calorimetry," Cement and Concrete Research, vol. 83, pp. 131-139, 2016.

[28] E. Gdoutos, M. Konsta-Gdoutos, and D. P.A., "Portland cement mortar nanocomposites at low carbon nanotube and carbon nanofiber content, a fracture mechanics experimental study," Cement and Concrete Research, vol. 70 , pp. 110-118, 2016 .

[29] A. Ghatefar, E. El-Salakawy, and M. Bassuoni, "Earlyage restrained shrinkage cracking of gfrp-rc bridge deck slabs: Effect of environmental conditions," Cement and Concrete Research, vol. 64, pp. 62-73, 2015.

[30] J. Wang, P. Basheer, and S. Nanukuttan, "Influence of service loading and the resulting micro-cracks on chloride resistance of concrete," Construction and Building Materials, vol. 108, pp. 56-66, 2016

[31] E. Roziere, A. Loukili, H. R.E., and F. Grondin, "Durability of concrete exposed to leaching and external sulphate attacks," Construction and Building Materials, vol. 39 , no. 12 , pp. $1188-1198,2009$.

[32] B. Tian and M. Chen, "Expansion of alite paste caused by gypsum formation during sulfate attack," Journal of Materials in Civil Engineering, vol. 12, no. 1, pp. 24-25, 2000.

[33] C. Navarroa and E. Doehnea, "Salt weathering: Influence of evaporation rate, supersaturation, and crystallization pattern," Earth Surface Processes and Landforms, vol. 24, no. 3, pp. 191-209, 1999.

[34] J. Duchesne and A. Bertron, "Leaching of Cementitious Materials by Pure Water and Strong Acids $(\mathrm{HCl}$ and HNO3)," in Performance of Cement-Based Materials in Aggressive Aqueous Environments, M. Alexander, A. Bertron, and N. De Belie, Eds., vol. 10. Springer, Dordrecht, 2013, rILEM State-of-the-Art Reports.

[35] M. Juenger and R. Siddique, "Recent advances in understanding the role of supplementary cementitious materials in concrete," Cement and Concrete Research, vol. 78, pp. 71-80, 2015 .

[36] A. Ramezanianpour and R. Hooton, "Sulfate resistance of portland-limestone cements in combination with supplementary cementitious materials," Materials and Structures, vol. 46, no. 7, pp. 1061-1073, 2013.

[37] P. Mazurok, T. Turgunov, V. Svidersky, and V. Tokarchuk, "Effect of calcium and magnesium oxides on the properties of expanding cement sand plugging mortars," Eastern-European Journal of Enterprise Technologies, vol. 4, no. 6, pp. 47-52, 2017. 